\title{
Improving juror comprehension: reading while listening ${ }^{1}$
}

\author{
Janet Randall \\ LSA Annual Meeting, Portland, Oregon, January 9-11, 2015
}

1. Background. A growing problem confronts US courtrooms: though all citizens over 18 qualify as jurors, jury instructions are often incomprehensible, especially to those with little education or rudimentary English (Charrow \& Charrow 1979; Elwork, et. al. 1982; Diamond 2003; Diamond, Murphy \& Rose 2012; Tiersma 2009). This excludes many jurors from equal participation but, worse, has led to misinformed verdicts (Benson 1985; Marder 2006). Many states are now taking action and a Massachusetts Bar Association Task Force -- aided by linguistics -- is joining them. The study reported here investigates the difficulties posed by jury instructions and possible solutions. Replicating research by Randall (2013) and Randall \& Graf (2014), we test the hypotheses that: [1] Massachusetts current jury instructions are harder to comprehend than "Plain English" versions and [2] the difficulties relate to linguistic features of the instructions. But here we add a third hypothesis: [3] reading while listening will improve comprehension over listening alone.

2. Previous Findings: Study 1 (Randall, 2013; Randall \& Graf, 2014) Our earlier work provided evidence for two hypotheses:

1. Current Jury Instructions are more difficult to understand than Plain English Jury Instructions.

2. Two linguistic factors significantly contribute to processing difficulty: passive verbs and presupposed terms.

Two groups of Northeastern University students (29 in each), listened to six recordings of either Current or Plain English jury instructions (after one "warm-up") and answered the same set of true/false questions after each instruction. Figure 1 shows significantly higher comprehension rates in the Plain English Listening condition than in the Current Listening condition, 84\% vs. 77\% ( $<$ <.05), confirming Hypothesis 1.

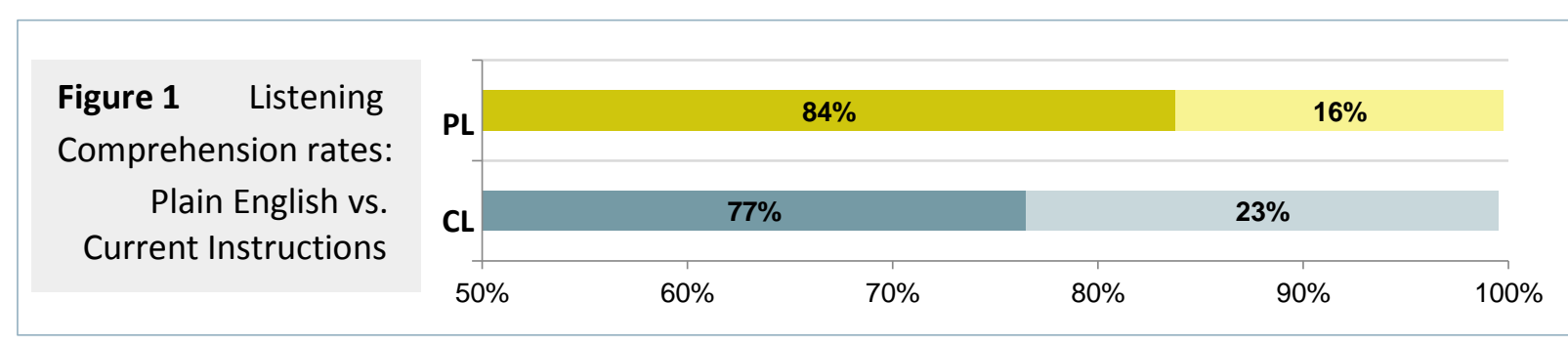

Confirming Hypothesis 2, comprehension varied across the instructions (Fig. 2a), inversely correlating with two linguistic factors (Fig. 2b): passive verbs and legalese terms. Results

\footnotetext{
${ }^{1}$ I am grateful to the Massachusetts Bar Association for grant support and for sponsoring me as a 2012-15 Visiting Research Fellow. The Northeastern University College of Social Sciences \& Humanities Research Development Fund and Undergraduate Research Initiative provided additional support. Thanks also go to the members of the MBA Plain English Jury Instruction Task Force, as well as to the other members of the Northeastern University Plain English Jury Instruction Project team, Alana Dore, Katherine Fiallo, Aaron McPherson, and Andrea Medrano, for their invaluable comments and suggestions.
} 
clustered in two groups: "easy" Instructions $1 \& 2$ contained lower rates of these two factors; "difficult" Instructions 3-6 contained higher rates.

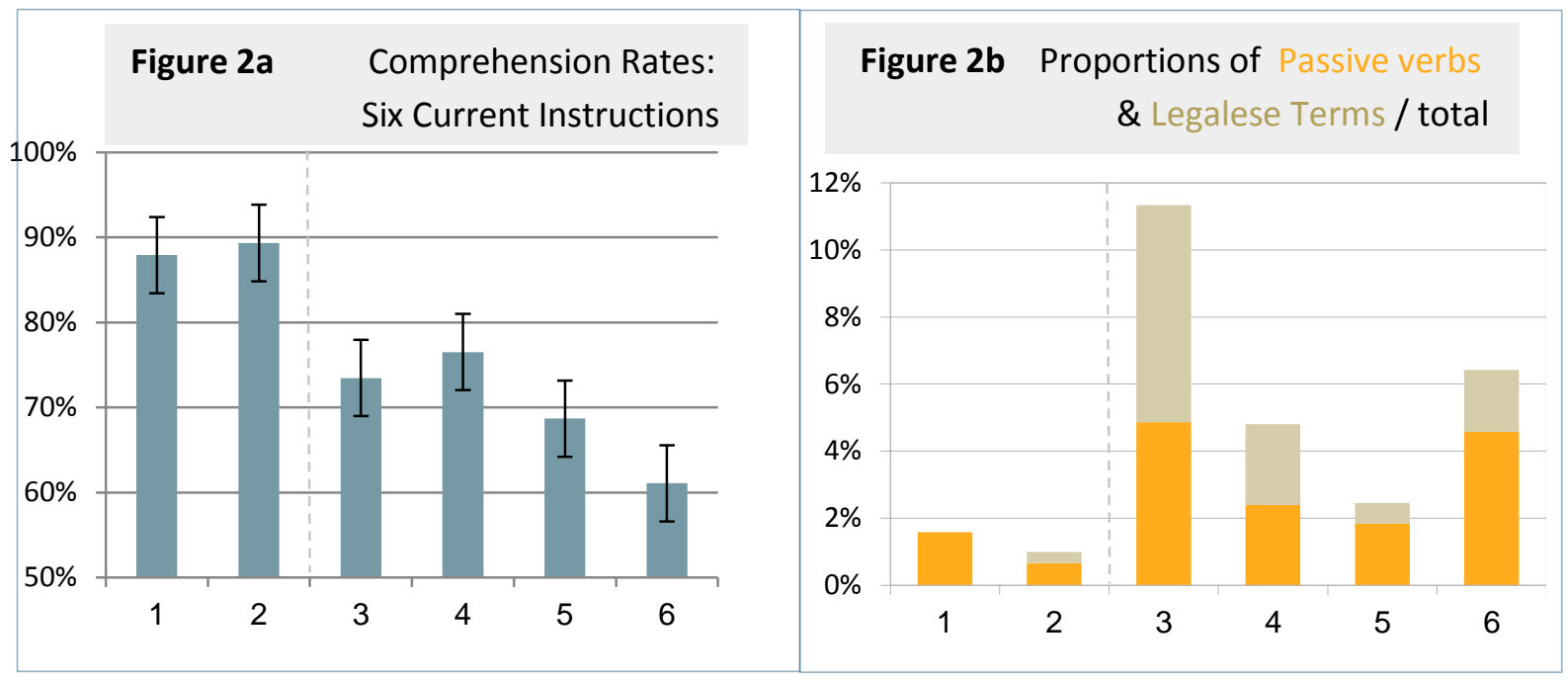

3. New Findings: The Current Study. The current study retested Hypotheses 1 and 2, using a larger subject pool and slightly modified Plain English instructions. In addition, we tested a new hypothesis, Hypothesis 3.

\section{Hypotheses}

1. Current Jury Instructions are more difficult to understand than Plain English Jury Instructions.

2. Two linguistic factors significantly contribute to processing difficulty: passive verbs and presupposed terms.

\section{Reading while listening improves comprehension over listening-only.}

As in our earlier study, subjects (214 Northeastern University undergraduates) listened to recordings of either 6 Current (C) or 6 Plain English (PE) instructions (plus one warm-up instruction) and answered true/false questions after each. The same $t / f$ questions were used for the Current and Plain English versions of each instruction.

Our new results (Fig. 3) reconfirm Hypothesis 1: Plain English jury instructions show numerically higher comprehension rates than Current Instructions for both Listening-only [86\% PL > 83\% CL] and Reading+listening [90\% PR > 87\% CR], though neither difference reached significance. These results also confirm our new Hypothesis 3: reading while listening showed an upward trend when compared with listening-only for both the Current [87\% CR > 83\% CL] and Plain English [90\% PR > 86\% PL] instructions.

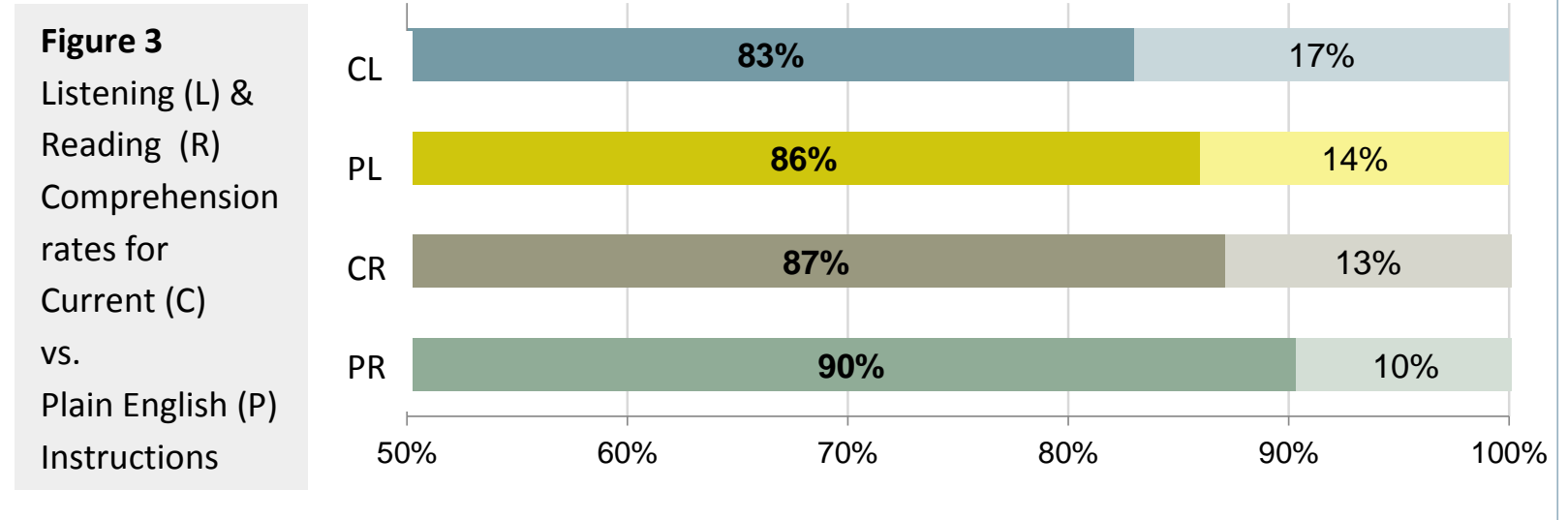


These new results also reconfirm Hypothesis 2: comprehension accuracy across the six current instructions, shown in Figure $4 \mathrm{a}$, inversely correlates $(\mathrm{r}=-0.7)$ with the rates of two linguistic factors that challenge processing (a) passive verbs (Ferreira 2003) and (b) "legalese" terms, as shown in Figure 4b (Diana \& Reder 2006). The instructions clustered in two groups. "Easy" current instructions $(1,2,4,5)$ contain lower combined rates of passive verbs and legalese terms (Figure 4b) than "difficult" instructions $(3,6)$.

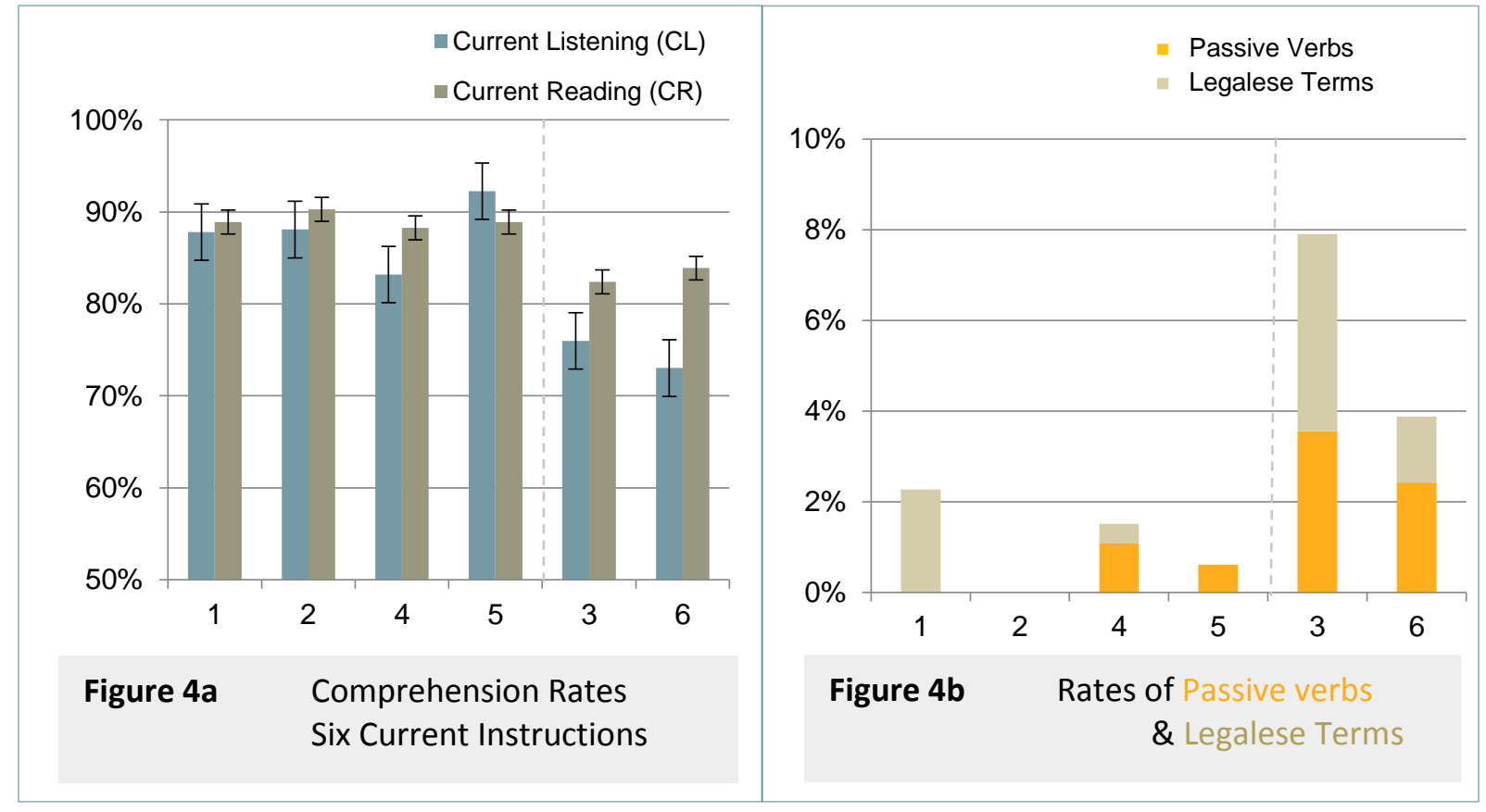

Figure 4a also shows a difference in the effect of reading on the two clusters: only for the "difficult" instructions $3 \& 6$ was improvement significant ( $p<.05$ for both).

4. A Case Study: Jury Instruction 3, Standard of Proof. The excerpts of the Current (left) and Plain English (right) instruction demonstrate the reason for the striking comprehension difference: a corresponding difference in the rates of passive verlos and legallese terms.

\section{Jury Instruction 3: Standard of Proof [excerpt]}

\section{Current Instruction}

The standard of proof in a civil case is that a plaintiff must prove his or her case by a preponderance of the evidence. This is a less stringent standard than is applied in a criminal case, where the prosecution must prove its case beyond a reasonable doubt. By contrast, in a civil case such as this one, the plaintiff is not required to prove his or her case beyond a reasonable doubt. In a civil case, the party bearing the burden of proof meets the burden when he or she shows it to be true by a preponderance of the evidence. The standard of a preponderance of the evidence means the greater weight of the evidence. A preponderance of the evidence is such evidence which, when considered and compared with any opposed to it, has more convincing force and produces in your minds a belief that what is sought to be proved is more probably true than not true.... (Brady et. al., 2008).

\section{Plain English Instruction}

This is a civil case. As in all civil cases, there is a "plaintiff" and a "defendant". The plaintiff is the party who brings the case against the defendant. And it is the plaintiff who "bears the burden of proof." This means that the plaintiff must present enough evidence to convince you of his or her case. What counts as enough evidence? In order for you to support the plaintiff, when you weigh all the evidence, you must find that the greater weight of the evidence - also called "the preponderance of the evidence" - supports the plaintiff's side. But if you find that the evidence supporting the defendant is stronger - or that the evidence on the two sides is equally strong - 50/50 - then you must decide in favor of the defendant. ... 
As predicted by Hypothesis 2, this instruction's relatively low Current comprehension scores (CL, CR in Figs. 4a \& 5a) correlate with its high rates of passive verbs and legalese terms (Figs. 4b \& 5b). And, as Figure 5a shows, the improved comprehension on the Plain English version, on both Listening-only [ $81 \% \mathbb{P L}>76 \% \mathrm{CL}$ ] and Reading+listening [ $89 \% \mathrm{PR}>82 \%$ CR], confirmed Hypothesis 1. Figure 5a also confirms Hypothesis 3: comprehension improved with the addition of reading, across both Current $[82 \% \mathrm{CR}>76 \% \mathrm{CL}]$ and Plain English instructions $[89 \% \mathrm{PR}>81 \% \mathrm{PL}]$. And the greatest difference is seen between the Current listening-only and Plain English Reading+listening conditions [89\% PR $>76 \% \mathrm{CL}]$.

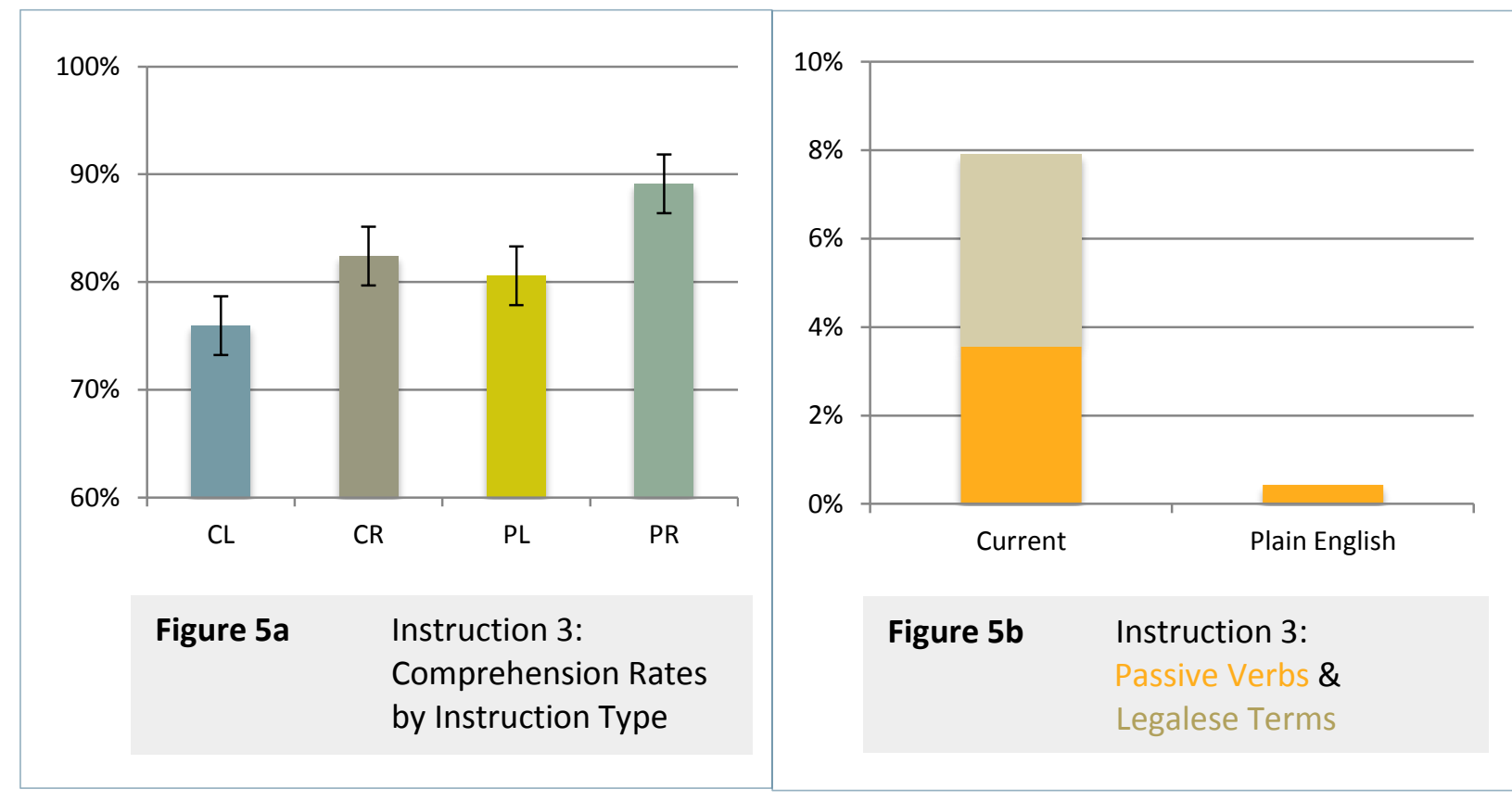

5. Discussion Though comprehension improved for both (1) Plain English over Current Instructions and (2) Reading + listening over Listening-only, the improvements were small, probably because the comprehension of current instructions was high overall (over 80\%), leaving little room for improvement. This may come from our subject pool, all Northeastern University undergraduates, who have higher educational levels than a typical jury; according to 2013 U.S. Census Bureau data, $42 \%$ of US residents over 18 have not gone beyond high school. We are now running a follow-up study using subjects with no college experience. If this new group shows greater differences in comprehension, we would have even stronger evidence for the Plain English Jury Instruction Task Force to make its case: better informed juries will reach more reliable verdicts only when Massachusetts jury instructions are rewritten and jurors are allowed to read them.

6. Conclusions Our three hypotheses were confirmed: Legal language can be made more comprehensible:

- Hypothesis 1 if it is rewritten in Plain English.

- Hypothesis 2 if complex linguistic factors - specifically, passive verbs and legalese terms are minimized.

- Hypothesis 3: if subjects can read the text of the instructions as they listen to them.

Though our student subjects showed only modest comprehension improvements when we made these changes to our instructions, we expect to see greater improvements for jurors, who have less formal education and fewer language skills. Overall, our studies provide support for Plain English efforts to reform legal language. Rewriting jury instructions into Plain English would improve justice by helping jurors to better understand the law and reach more reliable, and ultimately fairer, verdicts. 


\section{References}

Benson, Robert W. (1985) The end of legalese: the game* is over. Review of law \& social change 13, 519-579.

Brady, Patrick E. et al. (2008) Massachusetts Superior Court Civil Practice Jury Instructions $§ 2.1 .2$ Definition of Negligence, Massachusetts Continuing Legal Education, Inc. Boston, MA.

Brown, R., Waring, R., Donkaewbua, S., (2008). Incidental vocabulary acquisition from reading, reading-while-listening, and listening tostories. Reading in a Foreign Language 20, 136-163.

Chang, Anna C.-S. (2009) Gains to L2 listeners from reading while listening vs.listening-only in comprehending short stories. System 37, 652-663.

Charrow, Robert P. \& Veda R. Charrow (1979) Making Legal Language Understandable: A Psycholinguistic Study of Jury Instructions. Columbia Law Review 79, 1306-1374.

Diamond, Shari S. (2003) "Truth, Justice and the Jury," Harvard Journal of Law \& Public Policy 26, 143-155.

Diamond, Shari S., Beth Murphy \& Mary R. Rose (2012) The "kettleful of law" in real jury deliberations: successes, failures, and next steps. Northwestern University Law Review 106, No. 4, 1537- 1608.

Diana, Rachel A. \& Lynne M. Reder (2006) The Low-Frequency Encoding Disadvantage: Word Frequency Affects Processing Demands. Journal of Experimental Psychology: Learning, Memory, and Cognition 32, 805-815.

Elwork, Amiram, Bruce D. Sales \& James J. Alfini (1982) Making Jury Instructions Understandable. Michie, Charlottesville, VA.

Ferreira, Fernanda. (2003) he misinterpretation of noncanonical sentences. Cognitive Psychology 47,164-203.

Frank, James \& Brandon Applegate (1998) Assessing juror understanding of capital sentencing instructions. Crime and Deliquency 44, 412-433.

Randall, Janet (2013) Plain English Jury Instructions for Massachusetts: first steps. Paper presented at the Linguistics Society of America Annual Meeting, Boston, MA.

Randall, Janet \& Lucas Graf (2014) Linguistics meets "legalese": syntax, semantics, and jury instruction reform. Paper presented at the Linguistics Society of America Annual Meeting, Boston, MA.

Tiersma, Peter M. (2009) Communicating with Juries: How to Draft More Understandable Jury Instructions. Loyola-LA Legal Studies Paper No. 2009-44. Available at SSRN: http://ssrn.com/abstract=1507298.

U.S. Census Bureau (2013) Current Population Survey, 2013 Annual Social and Economic Supplement. Educational Attainment of the Population 18 Years and Over, by Age, Sex, Race, and Hispanic Origin: 2013, All Races. Accessed electronically on March 21, 2014. https://www.census.gov/hhes/socdemo/education/data/cps/2013/tables.html. 